\title{
In situ extraction (milking) of the two promising Botryococcus braunii strains Showa and Bot22 under optimized extraction time
}

\author{
Christian Kleinert $^{1}$ (D) $\cdot$ Carola Griehl $^{1}$ (D)
}

Received: 21 July 2021 / Revised and accepted: 14 October 2021 / Published online: 28 November 2021

(c) The Author(s) 2021, corrected publication 2022

\begin{abstract}
In situ extraction or "milking" of microalgae is a promising approach to reduce downstream costs in order to produce lowvalue substances such as lipids from microalgae in an economical way. Due to its ability to secrete high amounts of longchain hydrocarbons to an extracellular matrix, the green microalga Botryococcus braunii is suitable for the process of in situ extraction as the cost intensive steps of harvesting, dewatering, and cell disruption could be omitted. Based on a previous study investigating various $B$. braunii strains in terms of growth, lipid accumulation, and solvent compatibility, the B. braunii strains Showa and Bot22 (both B race) were identified as potential candidates for the process of in situ extraction. In order to prove the suitability of these two strains for the process of in situ extraction, this study first determined the optimal extraction time using short-term in situ extraction over 7 days at different starting biomass concentrations of 1.5 and $2.5 \mathrm{~g} \mathrm{~L}^{-1}$. Furthermore, both strains were treated applying the optimal extraction time in long-term in situ extractions for 30 days to confirm the results from the short-term extractions. The results indicate a strain-dependent optimal extraction time of $300 \mathrm{~min}^{-1 a y}{ }^{-1}$ for strain Showa and $200 \mathrm{~min} \mathrm{day}^{-1}$ for strain Bot22. During long-term in situ extraction for 30 days, hydrocarbon productivity was $16.99 \mathrm{mg} \mathrm{L}^{-1} \mathrm{day}^{-1}\left(10.53 \mathrm{mg} \mathrm{g}_{\mathrm{DW}}{ }^{-1} \mathrm{day}^{-1}\right)$ for strain Showa and $14.53 \mathrm{mg} \mathrm{L}^{-1}$ day $^{-1}\left(10.48 \mathrm{mg} \mathrm{g}_{\mathrm{DW}}{ }^{-1} \mathrm{day}^{-1}\right)$ for strain Bot22. Furthermore, a direct correlation between hydrocarbon productivity achieved by in situ extraction and the hydrocarbon concentration in the biomass of the respective strain could be established. It could be shown that the consideration of the effective extraction time and the phase boundary area is required to calculate an extraction system independent value for the comparison of different extraction setups.
\end{abstract}

Keywords Botryococcus braunii $\cdot$ Milking $\cdot$ In situ Extraction $\cdot$ Hydrocarbons $\cdot$ Microalgae

\section{Introduction}

The in situ extraction or "milking" of microalgae offers a promising approach to reduce the downstream costs of producing low-value products such as lipids from microalgae (Hejazi and Wijffels 2004; Borowitzka and Moheimani 2013; Griehl et al. 2015; Chaudry et al. 2018; Jackson et al. 2020; Kleinert and Griehl 2021). In the in situ extraction process, the microalgae culture suspension is extracted directly during the cultivation, eliminating the cost and energy intensive steps of harvesting, dewatering, and cell

Carola Griehl

carola.griehl@hs-anhalt.de

Christian Kleinert

christian.kleinert@hs-anhalt.de

1 Competence Center Algal Biotechnology, Anhalt University of Applied Sciences, Koethen, Germany disruption, which account for 50 to $80 \%$ of the total costs of the classical process chain (Acién et al. 2012; Khoo et al. 2020). Ideally, the culture suspension remains alive (non-destructive), can produce new product, and could be extracted multiple times like the daily "milking of a cow" (Moheimani et al. 2014; Griehl et al. 2015; Bhadana and Tyagi 2019; Jackson et al. 2019). Therefore, microalgal cells must synthesize substances that are actively secreted to the surrounding medium or an extracellular matrix around the cells. During in situ extraction, these extracellular substances were extracted from the culture by passing the culture suspension through a solvent or vice versa (Hejazi and Wijffels 2004; Griehl et al. 2015; Jackson et al. 2017).

A suitable microalga for the process of in situ extraction is Botryococcus braunii. This colony-forming green alga produces high amounts of long-chain hydrocarbons that are secreted into an extracellular matrix around the cells up to a concentration of $86 \%$ of the total dry weight (Borowitzka 
2018). Among the described B. braunii races A, B, L, and S (Kawachi et al. 2012), which differ in the chemical structure of extracellular hydrocarbons, the species of the B race that produce botryococcenes and methylsqualenes are of particular interest for biofuel production (Borowitzka 2018). Besides the active secretion of long-chain hydrocarbons, another advantage of $B$. braunii is the growth-associated production of these hydrocarbons (Kojima and Zhang 1999; Baba et al. 2012; Melis 2013) which is caused by the specific carbon partitioning during photosynthesis. In contrast to other plants, B. braunii utilizes $45 \%$ of the assimilated $\mathrm{CO}_{2}$ during photosynthesis for the synthesis of hydrocarbons and $45 \%$ for biomass production resulting in a high lipid content and a low growth rate (Melis 2013), making this alga unsuitable for classical treatment (Griehl et al. 2015; Jackson et al. 2017).

Due to these strain-specific properties, most research focusing on non-destructive in situ extraction during cultivation is conducted using $B$. braunii and only a few other microalgae have been investigated with regard to in situ extraction (Kleinert and Griehl 2021). Currently, two process methods are used for the in situ extraction of $B$. braunii. Firstly, systems based on the principle of a mixersettler, in which the culture suspension is mixed with the solvent by stirring in the same system (Choi et al. 2013; Moheimani et al. 2013, 2014; Jackson et al. 2019), and secondly, column extractors, in which the culture suspension flows through an extraction column filled with solvent (An et al. 2004; Zhang et al. 2013; Griehl et al. 2015; Mehta et al. 2019), have been used. As both principles generally belong to the category of liquid-liquid extractions, the phase transition of the long-chain hydrocarbons from the culture suspension to the solvent is influenced by the dispersion of the culture suspension in the solvent using either a stirrer (mixer-settler) or a nozzle (column extractor). The aim of dispersion is thus to generate the highest possible phase interface and the longest possible effective extraction time (Räbiger et al. 2010; Schlüter 2018). For the in situ extraction of long-chain hydrocarbons from $B$. braunii, solvents such as $n$-hexane, $n$-heptane, or $n$-dodecane with a non-polar character are required (Moheimani et al. 2014; Griehl et al. 2015; Jackson et al. 2017). Since these solvents exert a negative influence on the vitality of the B. braunii cells and the cells are to be kept alive for repeated extraction, a compromise between the extraction efficiency of the hydrocarbons and cell vitality must be found for the in situ extraction of this alga (Moheimani et al. 2014).

Currently, only a handful of strains among the $B$. braunii have been investigated for repeated non-destructive in situ extraction with variations in setups for the extraction process, solvents, extraction times, and extraction cycles (Kleinert and Griehl 2021). These variations in experimental setups and methods make it difficult to compare the respective studies and prevent the derivation of characteristic strain-specific parameters such as optimal extraction time for establishing an in situ extraction process. In this study, the two B. braunii strains Showa and Bot22 (B race) were to be evaluated for the in situ extraction process developed at Anhalt University of Applied Sciences (Griehl et al. 2015). Therefore, these two strains, identified as potential candidates for the in situ extraction procedure in a previous study (Kleinert and Griehl 2021), were characterized in terms of optimal extraction time for short-term in situ extractions by gradually increasing the daily extraction time while treating with the solvent $n$-hexane. By calculating the culture system independent extraction coefficient $\left(A t_{\text {EXT,eff }}\right)$, which is the product of effective extraction time and phase boundary area, the determined strain-specific optimal extraction time was applied to in situ extractions over 30 days to evaluate the long-term effect of the optimized extraction time. The aim of this study was to demonstrate the applicability of the in situ extraction process for the strains Showa and Bot22 previously identified as potential candidates. With regard to an easy transfer and scale-up of the in situ extraction process to other or larger cultivation and extraction systems, the calculation of the extraction coefficient $\left(A t_{\mathrm{EXT}, \mathrm{eff}}\right)$ is suitable as a key parameter.

\section{Materials and methods}

\section{Microorganisms and growth conditions}

The two Botryococcus braunii strains Showa and Bot22 were obtained from Shigeru Okada of the Faculty and Graduate School of Agriculture and Life Science of the University of Tokyo and Makoto M. Watanabe of the Algae Biomass and Energy System R\&D Center of the University of Tsukuba, respectively. Both strains were maintained in BG11 medium (Rippka et al. 1979) in 1.5-L bubble columns with continuous light at $100 \mu \mathrm{mol}$ photons $\mathrm{m}^{-2} \mathrm{~s}^{-1}$ (LED Panel, $80 \mathrm{~W}$, $6500 \mathrm{~K}$, daylight), at a temperature of $26^{\circ} \mathrm{C}$ and a gas flow rate of $1 \mathrm{vvm}$ enriched with $1 \% \mathrm{CO}_{2} \mathrm{v} / \mathrm{v}$ before being used for in situ extraction.

\section{Biomass determination}

Biomass was determined gravimetrically in triplicate and described in terms of dry weight per culture volume $\left(\mathrm{g} \mathrm{L}^{-1}\right)$. Biomass was measured by filtering the algal suspension through pre-weighed 24-mm glass fiber filters (VWR 693). Filters containing biomass were rinsed three times with ultrapure water to remove residual salts of the culture medium. Washed filters were dried at $104{ }^{\circ} \mathrm{C}$ for $12 \mathrm{~h}$ and stored in a desiccator for $30 \mathrm{~min}$ before being weighed. 


\section{Extracellular hydrocarbon determination}

Extracellular hydrocarbon content (amount of hydrocarbons kept in the colonies after filtration) was measured gravimetrically according to the method described in a previous study (Kleinert and Griehl 2021). The dried 24-mm glass fiber filters (VWR 693) were transferred to 40-mL glass vials, $3 \mathrm{~mL} n$-hexane was added to the filter, and the glass vials were closed with a screw cap. After $24 \mathrm{~h}$ at room temperature, the solvent was transferred to pre-weighed $20-\mathrm{mL}$ glass vials by filtration through $0.2-\mu \mathrm{m}$ PTFE filters (Restek $13 \mathrm{~mm}$ syringe filter). The filter-containing $40-\mathrm{mL}$ glass vials were rinsed twice more with $3 \mathrm{~mL} n$-hexane. Supernatants were pooled and evaporated to dryness using a vacuum evaporator (Hettich Combi Dancer) at $39{ }^{\circ} \mathrm{C}$ and $300 \mathrm{rpm}$. The glass vials were weighed again to obtain the extracellular amount of hydrocarbon kept in the colonies after filtration.

\section{Calculation of the extraction coefficient}

The extraction coefficient $A t_{\text {EXT,eff }}$ (Eq. 1) was calculated as the product of the generated boundary area between culture suspension and solvent phase per liter culture volume $A_{\text {EXT,eff }}$ (Eq. 2) and the effective extraction time $t_{\text {EXT,eff }}$ (Eq. 3), i.e., the time each culture suspension droplet (droplet of culture suspension which contains several colonies of $B$. braunii and subsequently mentioned as particle) remains in contact with solvent. These equations are composed of the total extracted culture suspension volume $\left(V_{\mathrm{EXT}}\right)$, the reactor volume $\left(V_{\mathrm{R}}\right)$, and the culture suspension particle-related values of the particle retention time in the solvent phase $\left(t_{\mathrm{R}, \mathrm{d}_{\mathrm{P}}}\right)$, particle surface area $\left(A_{\mathrm{P}}\right)$, particle volume $\left(V_{\mathrm{P}}\right)$, and relative sinking velocity of the particle $\left(w_{\mathrm{r}}\right)$.

$A t_{\mathrm{EXT}, \mathrm{eff}}=A_{\mathrm{EXT}, \mathrm{eff}} t_{\mathrm{EXT}, \text { eff }}$

$A_{\mathrm{EXT}, \mathrm{eff}}=\frac{V_{\mathrm{EXT}} A_{\mathrm{P}}}{V_{\mathrm{P}}}$

$t_{\mathrm{EXT}, \mathrm{eff}}=\frac{V_{\mathrm{EXT}}}{V_{\mathrm{R}}} t_{\mathrm{R}, \mathrm{d}_{\mathrm{P}}}$

For the calculation of the culture particle-related values, the particle diameter $\left(d_{\mathrm{P}}\right)$ is required. Considering a periodic formation of the primary particles at the outlet of the disperser, $d_{\mathrm{P}}$ was calculated by iteratively solving Eq. 4 (Räbiger et al. 2010), where $F_{\eta}$ is the viscous force (Eq. 5), $F_{\mathrm{T}}$ is the inertial force (Eq. 6), $F_{\sigma}$ is the surface tension force (Eq. 7), $\Delta \rho$ is the density difference between culture suspension and solvent, $g$ is the gravitational force $\left(\mathrm{g}=9.81 \mathrm{~m} \mathrm{~s}^{-1}\right), \eta_{\mathrm{K}}$ is the viscosity of the continuous (solvent) phase, $V_{\mathrm{D}}$ is the flow rate of the dispersed (culture suspension) phase, $\rho_{\mathrm{K}}$ is the density of the continuous (solvent) phase, $d_{\mathrm{N}}$ is the diameter of the disperser outlet, and $\sigma$ is the surface tension of the culture suspension dispersed in the solvent.

$d_{\mathrm{P}}=\left[\left(\frac{F_{\eta}+F_{\mathrm{T}}+F_{\sigma}}{\Delta \rho * g}\right) \frac{6}{\pi}\right]^{\frac{1}{3}}$

$F_{\eta}=15 \eta_{\mathrm{K}} \frac{V_{\mathrm{D}}}{d_{\mathrm{P}}}$

$F_{\mathrm{T}}=1.3 \rho_{\mathrm{K}}\left(\frac{V_{\mathrm{D}}}{d_{\mathrm{p}}}\right)^{2}$

$F_{\sigma}=\pi d_{\mathrm{N}} \sigma$

With the iterative determined $d_{\mathrm{P}}$, the particle surface area $\left(A_{\mathrm{P}}\right)$ and the particle volume $\left(V_{\mathrm{P}}\right)$ were calculated with Eq. 8 and Eq. 9, respectively.

$A_{\mathrm{P}}=\pi d_{\mathrm{P}}^{2}$

$V_{\mathrm{P}}=\frac{4}{3} \pi\left(\frac{d_{\mathrm{P}}}{2}\right)^{3}$

The relative sinking velocity of the culture suspension particle in the solvent $\left(w_{\mathrm{r}}\right)$ was calculated with Eq. 10. Therefore, the culture suspension particle-related Reynolds number $\left(\operatorname{Re}_{\mathrm{P}}\right)$, the viscosity $\left(\eta_{\mathrm{K}}\right)$, and the density $\left(\rho_{\mathrm{K}}\right)$ of the continuous (solvent) phase as well as the culture suspension particle diameter $\left(d_{\mathrm{P}}\right)$ are required (Räbiger et al. 2010)

$w_{\mathrm{r}}=\frac{\operatorname{Re}_{\mathrm{P}} \eta_{\mathrm{K}}}{d_{\mathrm{P}} \rho_{\mathrm{K}}}$

For the calculation of $\mathrm{Re}_{\mathrm{P}}$, the Archimedes number $\mathrm{Ar}$ (Eq. 11) and the liquid key number $K_{\mathrm{F}, \Delta \rho}$ (Eq. 12) are required. From this, $\operatorname{Re}_{\mathrm{P}}$ was calculated as a function of droplet diameter using one of Eq. 13 (symmetrical, non-oscillating droplets), Eq. 14 (internally circulating droplets), or Eq. 15 (deformable droplets) (Räbiger et al. 2010).

$$
\begin{gathered}
\mathrm{Ar}=\frac{d_{\mathrm{P}}^{3} g \rho_{\mathrm{K}} \Delta \rho}{\eta_{\mathrm{K}}^{2}} \\
K_{\mathrm{F}, \Delta \rho}=\frac{\rho_{\mathrm{K}} \sigma^{3}}{g \eta_{\mathrm{K}}^{4}} \frac{\rho_{\mathrm{K}}}{\Delta \rho}
\end{gathered}
$$


$\operatorname{Re}_{\mathrm{P}}=\frac{1}{18} \mathrm{Ar} \quad$ for $\quad \mathrm{Ar} \leq 1.83 \mathrm{~K}_{\mathrm{F}, \Delta \rho}^{0,275}$

$\operatorname{Re}_{\mathrm{P}}=K_{\mathrm{F}, \Delta \rho}^{0.15}\left(\mathrm{Ar}^{0.523} K_{\mathrm{F}, \Delta \rho}^{-0.1435}-0.75\right) \quad$ for $\quad 1.83 K_{\mathrm{F}, \Delta \rho}^{0.275} \leq \mathrm{Ar} \leq 372.9 K_{\mathrm{F}, \Delta \rho}^{0.275}$

$\operatorname{Re}_{\mathrm{P}}=K_{\mathrm{F}, \Delta \rho}^{0.15}\left(4.18 \mathrm{Ar}^{0.281} K_{\mathrm{F}, \Delta \rho}^{-0.0773}-0.75\right)$ for $\mathrm{Ar} \geq 372.9 K_{\mathrm{F}, \Delta \rho}^{0.275}$

With the relative sinking velocity $w_{\mathrm{r}}$, the retention time of the generated particles in the solvent $\left(t_{\mathrm{R}, \mathrm{d}_{\mathrm{P}}}\right)$ was calculated using Eq. 16, where $h_{\mathrm{S}}$ is the height of the solvent in the extraction column.

$t_{\mathrm{R}, \mathrm{d}_{\mathrm{P}}}=\frac{w_{\mathrm{r}}}{h_{\mathrm{S}}}$

The total volume of extracted culture suspension $\left(V_{\mathrm{EXT}}\right)$ was calculated using Eq. 17 , where $t_{\mathrm{EXT}}$ is the daily applied extraction time.

$V_{\mathrm{EXT}}=\dot{V}_{\mathrm{D}} t_{\mathrm{EXT}}$

The values used for the calculation of $A t_{\mathrm{EXT}, \text { eff }}, A_{\mathrm{EXT} \text {,eff }}$, and $t_{\mathrm{EXT} \text {,eff }}$ for extraction time $t_{\mathrm{EXT}}$, which apply to both $B$. braunii strains examined in this study, are shown in Table 1. For a better understanding of the calculation, an example is given in the supplementary material (ESM 1).

\section{Experimental design}

To determine the strain-dependent optimal extraction time of the B. braunii strains Showa and Bot22, short-term in situ extractions were carried out in extraction systems consisting of a 3-L bubble column cultivation system with an extraction column attached (Fig. 1) (Griehl et al. 2015). Experiments were conducted over 7 days with daily extraction times of 50,100, 150, 200, 250, 300, and $350 \mathrm{~min}$ for each strain using the solvent $n$-hexane. The biomass concentration in the culture suspension was adjusted to 1.5 or $2.5 \mathrm{~g} \mathrm{~L}^{-1}$ before the start of the short-term experiment. The culture suspension was illuminated with continuous light at $100 \mu \mathrm{mol}$ photons $\mathrm{m}^{-2} \mathrm{~s}^{-1}$ (LED Panel, $80 \mathrm{~W}, 6500 \mathrm{~K}$, daylight), maintained at a temperature of $26^{\circ} \mathrm{C}$, and a gas flow rate of $1 \mathrm{vvm}$ enriched with $1 \% \mathrm{CO}_{2} \mathrm{v} / \mathrm{v}$ was applied. Culture biomass concentration, nutrient concentration, and extracted hydrocarbons were analyzed daily. Nutrients in terms of nitrogen and phosphorus were supplemented daily
Table 1 Parameters for the calculation of the extraction coefficient $A t_{\text {EXT,eff }}$ based on the extraction time investigated
Fig. 1 Schematic illustration of the in situ extraction process based on Griehl et al. (2015) (left) and photograph of the in situ extraction apparatuses at Anhalt University of Applied Sciences (right)

\begin{tabular}{|c|c|c|c|c|c|c|c|c|}
\hline$t_{E X T}$ & {$[\mathrm{~min}]$} & 50 & 100 & 150 & 200 & 250 & 300 & 350 \\
\hline$\eta_{K}(n$-hexane $)$ & {$[P a s]$} & \multicolumn{7}{|l|}{0.00032} \\
\hline$\dot{V}_{D}($ culture $)$ & $\begin{array}{l}{\left[\operatorname{L~min}^{-1} / m^{3}\right.} \\
\left.s^{-1}\right]\end{array}$ & \multicolumn{7}{|c|}{$0.11811 / 1.9685 \mathrm{E}^{-6}$} \\
\hline$\rho_{K}(n$-hexane $)$ & {$\left[\mathrm{kg} \mathrm{m}^{-3}\right]$} & \multicolumn{7}{|l|}{660} \\
\hline$d_{N}($ disperser diameter $)$ & {$[m]$} & \multicolumn{7}{|l|}{0.005} \\
\hline$\rho_{D}($ culture $)$ & {$\left[\mathrm{kg} \mathrm{m}^{-3}\right]$} & \multicolumn{7}{|l|}{997} \\
\hline$\Delta_{\rho}($ culture $/ n$-hexane $)$ & {$\left[\mathrm{kg} \mathrm{m}^{-3}\right]$} & \multicolumn{7}{|l|}{337} \\
\hline$\sigma($ culture/ $n$-hexane) & {$\left[N \mathrm{~m}^{-1}\right]$} & \multicolumn{7}{|c|}{0.05038} \\
\hline$d_{P}($ iterative calculated $)$ & {$[\mathrm{mm}]$} & \multicolumn{7}{|l|}{7.879} \\
\hline$V_{R}($ reactor volume $)$ & {$[L]$} & \multicolumn{7}{|l|}{3} \\
\hline$h_{S}($ solvent height $)$ & {$[m]$} & \multicolumn{7}{|l|}{0.2} \\
\hline$t_{E X T, e f f}$ & {$[s]$} & 2.15 & 4.30 & 6.45 & 8.61 & 10.76 & 12.91 & 15.06 \\
\hline$A_{E X T, e f f}$ & {$\left[m^{2} L_{\text {Susp }}^{-1}\right]$} & 5.996 & 11.992 & 17.989 & 23.985 & 29.981 & 35.977 & 41.973 \\
\hline$A t_{E X T, \text { eff }}$ & {$\left[m^{2} s L_{\text {Susp }}^{-1}\right]$} & 12.90 & 51.61 & 116.12 & 206.44 & 322.56 & 464.49 & 631.22 \\
\hline
\end{tabular}

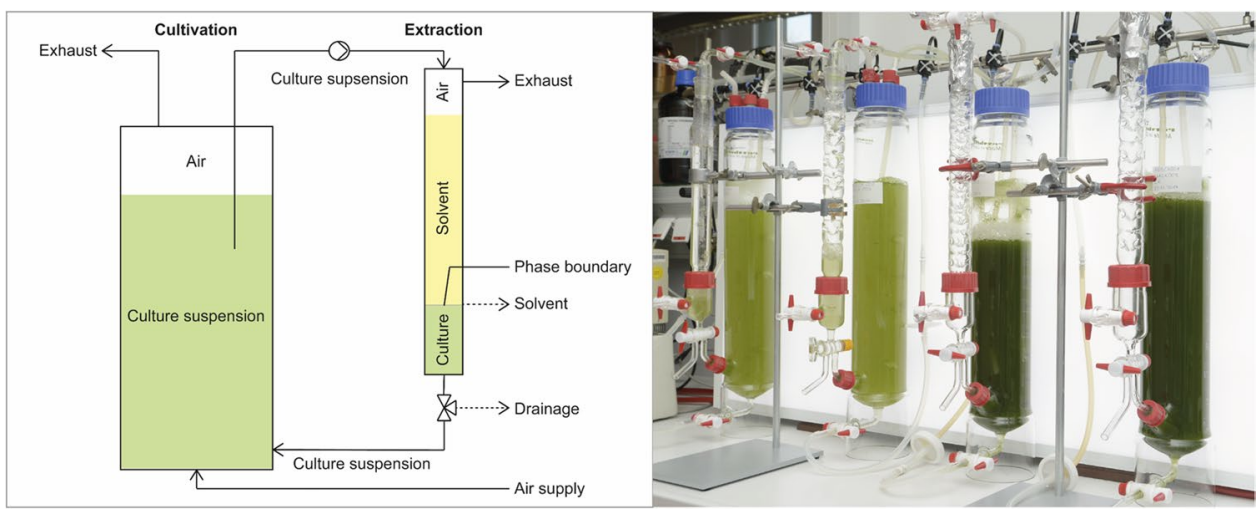


according to the initial BG11-media (Rippka et al. 1979) concentration before starting the in situ extraction. Each experiment was performed with three biological replicates.

To evaluate the determined optimal extraction time, long-term in situ extractions with the two $B$. braunii strains Showa and Bot 22 were carried out over 30 days with daily extraction under the optimal extraction time with the same extraction setup as described in the short-term experiments. External hydrocarbon concentration in the biomass was determined daily to investigate extraction-related effects on culture behavior. Each experiment was carried out with three biological replicates.

\section{Statistical analysis}

Statistical analyses were performed using OriginPro 2021 with one-way ANOVA to determine differences between strains $(p<0.05)$. For pairwise comparison of strains, the Holm-Sidak method was applied with $p<0.05$. Results were expressed as mean \pm standard deviation.

\section{Results}

\section{Optimization of extraction time in short-term in situ extraction}

The results of the short-term in situ extractions to investigate the optimal extraction time for the B. braunii strains Showa and Bot22 (Fig. 2) are displayed in Figs. 3 and 4, and summarized in terms of average biomass productivity, as well as daily volumetric and biomass-associated hydrocarbon productivity in Table 2. Under increasing extraction time with increasing increments of $50 \mathrm{~min} \mathrm{day}^{-1}$ in the range of 50 to $350 \mathrm{~min} \mathrm{day}^{-1}$, an increase in biomass concentration was observed for strain Showa during the 7 days of the in situ extraction experiment up to an extraction time of $250 \mathrm{~min} \mathrm{day}^{-1}$, while biomass growth was observed for strain Bot22 until an extraction time of 150 min day $^{-1}$ was reached (Fig. 3). At a daily extraction time of $300 \mathrm{~min}$ for strain Showa and 200 min for strain Bot22, a stagnation of the biomass concentration with minor fluctuations around the respective starting point of biomass concentration in the culture suspension was observed. With a further increase of the extraction time to $350 \mathrm{~min}^{\mathrm{day}}{ }^{-1}$ for strain Showa and to 250 min day $^{-1}$ for strain Bot22, a decrease of the biomass concentration in the culture suspension could be seen. When investigating the effect of the starting biomass concentration of the culture suspension, an identical trend was observed for the development of the biomass concentration of the culture suspension when varying the starting biomass concentration from 1.5 to $2.5 \mathrm{~g} \mathrm{~L}^{-1}$. For both strains and both starting biomass concentrations, the increase in culture density decreased with increasing daily extraction time.

Comparing the average biomass productivity of strain Showa during the short-term in situ extraction experiments for both starting biomass concentrations, a positive biomass productivity was measured up to an extraction time of $200 \mathrm{~min} \mathrm{day}^{-1}$. In the range of 50 to $150 \mathrm{~min}$ day $^{-1}$, no significant differences in biomass productivity were detected (ANOVA, $F_{35,41}=155.01, p<0.05 / \mathrm{Holm}$-Sidak, $t \leq-1.89, p>0.05)$. For the extraction times of 250 and $300 \mathrm{~min} \mathrm{day}^{-1}$, an average biomass productivity ranging from $-0.002 \pm 0.006$ to $0.023 \pm 0.008 \mathrm{~g} \mathrm{~L}^{-1} \mathrm{day}^{-1}$ $\left(c_{\text {DW,Start }}=1.5 \mathrm{~g} \mathrm{~L}^{-1}\right)$ and $-0.011 \pm 0.021$ to $0.042 \pm 0.021 \mathrm{~g} \mathrm{~L}^{-1} \mathrm{day}^{-1}\left(c_{\mathrm{DW}, \mathrm{Start}}=2.5 \mathrm{~g} \mathrm{~L}^{-1}\right)$ was observed. No significant differences were observed between the two extraction times (250 and $300 \mathrm{~min}^{-1} \mathrm{day}^{-1}$ ) (ANOVA, $F_{35,41}=155.01, p<0.05 / \mathrm{Holm}$-Sidak, $t=-2.45$, $p>0.05$ ). Increasing the extraction time to $350 \mathrm{~min}^{\mathrm{day}}{ }^{-1}$ resulted in a negative average biomass productivity of $-0.106 \pm 0.022 \mathrm{~g} \mathrm{~L}^{-1} \mathrm{day}^{-1}\left(c_{\mathrm{DW}, \mathrm{Start}}=1.5 \mathrm{~g} \mathrm{~L}^{-1}\right)$ and $-0.110 \pm 0.026 \mathrm{~g} \mathrm{~L}^{-1} \mathrm{day}^{-1}\left(c_{\mathrm{DW}, \text { Start }}=2.5 \mathrm{~g} \mathrm{~L}^{-1}\right)$ for both starting biomass concentrations. Positive average biomass productivity was measured for strain Bot 22 at extraction times of 50,100, and $150 \mathrm{~min} \mathrm{day}^{-1}$ for both starting biomass
Fig. 2 Microscopic images of the two examined B. braunii strains Showa (left) and Bot22 (right)
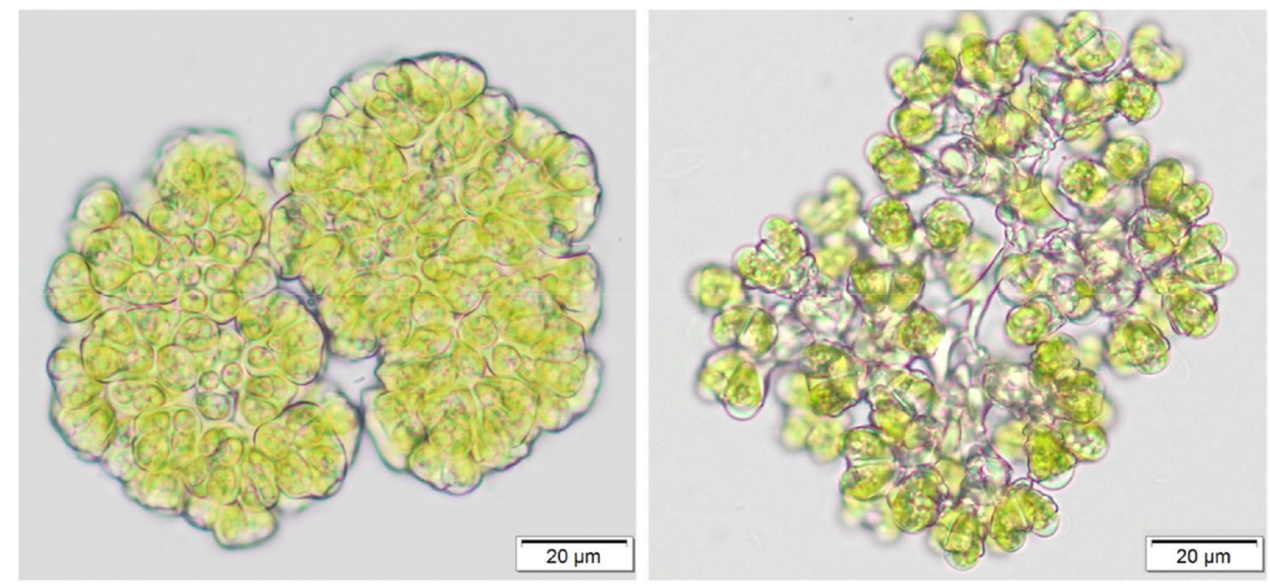
Fig. 3 Growth curves of the two investigated $B$. braunii strains Showa (left) and Bot22 (right) during a 7-day short-term in situ extraction with daily extraction times of 50,100, 150, 200, 250, 300 , and 350 min at a starting biomass concentration of 1.5 $\mathrm{g} \mathrm{L}^{-1}$ (top) and $2.5 \mathrm{~g} \mathrm{~L}^{-1}$ (bottom). Values represent mean \pm $\mathrm{SD}(n=3)$
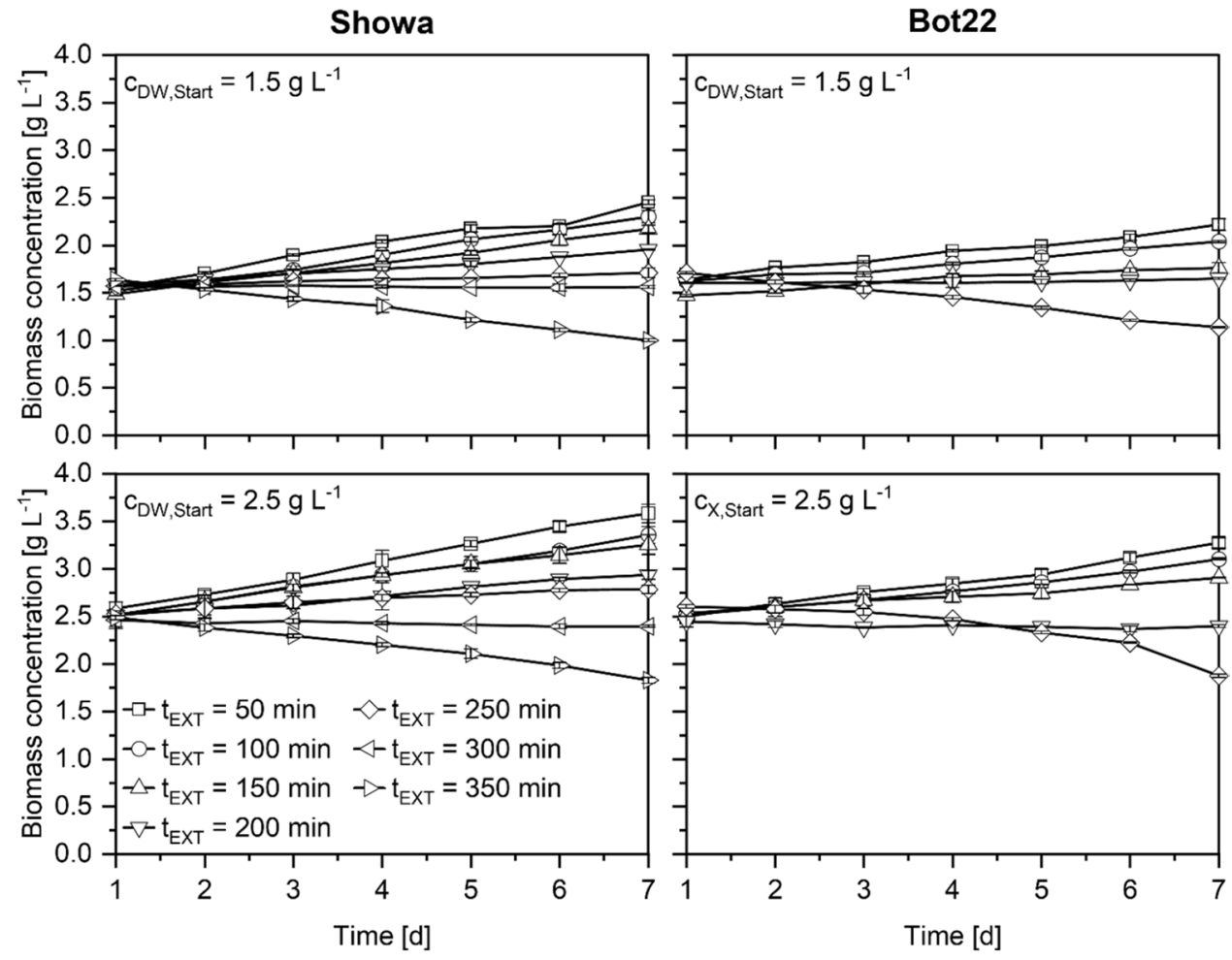

concentrations. Comparable to strain Showa, no significant differences were observed between the determined biomass productivity and the respective extraction times of 50, 100, and $150 \mathrm{~min}^{-1 a y}{ }^{-1}$ (ANOVA, $F_{25,29}=56.43, p<0.05 /$ Holm-Sidak, $t \geq-1.82, p>0.05$ ). An average biomass productivity around zero with $0.007 \pm 0.009 \mathrm{~g} \mathrm{~L}^{-1} \mathrm{day}^{-1}$ $\left(c_{\text {DW,Start }}=1.5 \mathrm{~g} \mathrm{~L}^{-1}\right)$ and $-0.008 \pm 0.027 \mathrm{~g} \mathrm{~L}^{-1} \mathrm{day}^{-1}$ $\left(c_{\mathrm{DW}, \mathrm{Start}}=2.5 \mathrm{~g} \mathrm{~L}^{-1}\right)$ was measured for strain Bot22 at an extraction time of $200 \mathrm{~min} \mathrm{day}^{-1}$. Further increase in extraction time resulted in a significant negative average biomass productivity (ANOVA, $F_{25,29}=56.43, p<0.05 / \mathrm{Holm}$-Sidak, $t \geq-6.05, p<0.05)$. The optimal extraction time, at which the average biomass productivity approached zero, varied between the strains investigated. While an extraction time of $300 \mathrm{~min}^{\mathrm{day}}{ }^{-1}$ was determined for the strain Showa, an extraction time of $200 \mathrm{~min}^{\text {day }}{ }^{-1}$ is optimal for strain Bot22.

Considering the hydrocarbon productivity during the short-term in situ extraction experiments in correlation with the respective extraction time, an increase in hydrocarbon productivity with increasing extraction time was observed for both strains and starting biomass concentrations. At the strain-dependent optimum extraction time of $300 \mathrm{~min} \mathrm{day}^{-1}$ for strain Showa and at $200 \mathrm{~min} \mathrm{day}^{-1}$ for strain Bot22, an average volumetric hydrocarbon productivity of $16.185 \pm 1.202$ and $16.750 \pm 2.318 \mathrm{mg} \mathrm{L}^{-1} \mathrm{day}^{-1}$, respectively, was measured in the experiments with a starting biomass concentration of $1.5 \mathrm{~g} \mathrm{~L}^{-1}$. For the starting biomass concentration of $2.5 \mathrm{~g} \mathrm{~L}^{-1}$, there was a significantly higher volumetric hydrocarbon productivity of $26.102 \pm 2.675 \mathrm{mg} \mathrm{L}^{-1}$ day $^{-1}$ for strain Showa (ANOVA, $F_{12,13}=68.59, p<0.05$ ) and of $25.701 \pm 1.378 \mathrm{mg} \mathrm{L}^{-1} \mathrm{day}^{-1}$ for strain Bot22 (ANOVA, $F_{12,13}=162.44, p<0.05$ ) compared to the values measured at a starting biomass concentration of $1.5 \mathrm{~g} \mathrm{~L}^{-1}$. Based on the biomass in the cultivation system at the strain-dependent optimal extraction time, a biomass-associated hydrocarbon productivity of $10.632 \pm 0.759 \mathrm{mg}_{\mathrm{DW}}{ }^{-1}$ day $^{-1}$ at $c_{\mathrm{DW}, \mathrm{Start}}=1.5 \mathrm{~g} \mathrm{~L}^{-1}$ and $10.655 \pm 1.171 \mathrm{mg}_{\mathrm{DW}}{ }^{-1} \mathrm{day}^{-1}$ at $c_{\mathrm{DW}, \mathrm{Start}}=2.5 \mathrm{~g} \mathrm{~L}^{-1}$ was achieved for strain Showa. For strain Bot22 and the optimum extraction time of $200 \mathrm{~min} \mathrm{day}^{-1}$, biomass-associated hydrocarbon productivities of $10.479 \pm 1.294 \mathrm{mg}_{\mathrm{DW}}{ }^{-1}$ day $^{-1}$ at $c_{\mathrm{DW}, \text { Start }}=1.5 \mathrm{~g} \mathrm{~L}^{-1}$ and $10.813 \pm 0.579 \mathrm{mg}_{\mathrm{DW}}{ }^{-1} \mathrm{day}^{-1}$ at $c_{\mathrm{DW}, \mathrm{Start}}=2.5 \mathrm{~g} \mathrm{~L}^{-1}$ were obtained. No significant differences were measured in hydrocarbon productivity between both strains and both starting biomass concentrations when the strain-dependent optimal extraction time was applied (ANOVA, $F_{24,27}=0.0055, p=0.941$ ).

\section{Long-term in situ extraction under optimal extraction time}

The results for the long-term in situ extraction of the two B. braunii strains Showa and Bot 22 over 30 days under the respective strain-dependent optimal extraction time of 300 
Fig. 4 Average biomass productivity (top), volumetric productivity of extracted hydrocarbons (middle), and biomass-associated productivity of extracted hydrocarbons (bottom) of the two examined B. braunii strains Showa and Bot22 during a 7-day short-term in situ extraction with daily extraction times of 50,100, 150, 200, 250,300, and $350 \mathrm{~min}$ at a starting biomass concentration of $1.5 \mathrm{~g} \mathrm{~L}^{-1}$ (left) and $2.5 \mathrm{~g} \mathrm{~L}^{-1}$ (right). Values represent mean $\pm \mathrm{SD}(n=3)$
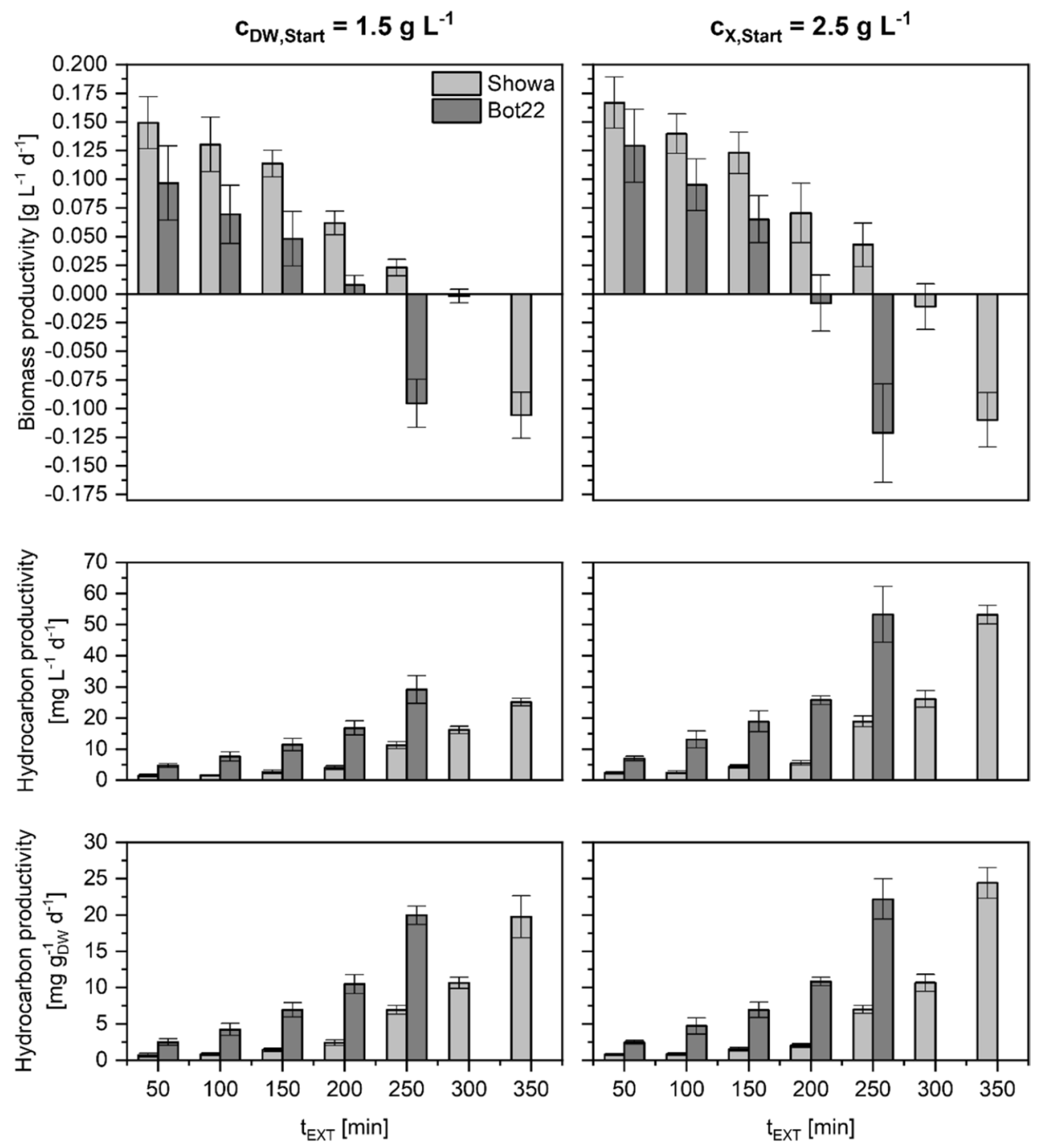

and 200 min day $^{-1}$ are displayed in Fig. 5 and summarized in Table 3. Figure 5A refers to the biomass concentration in the culture system over the experimental duration of 30 days, which fluctuated around the starting biomass concentration of $1.5 \mathrm{~g} \mathrm{~L}^{-1}$ (Showa: average biomass concentration $1.619 \pm 0.238 \mathrm{~g} \mathrm{~L}^{-1}$, maximum $1.968 \pm 0.019 \mathrm{~g} \mathrm{~L}^{-1}$, minimum $1.164 \pm 0.027 \mathrm{~g} \mathrm{~L}^{-1}$; Bot22: average biomass concentration $1.538 \pm 0.135 \mathrm{~g} \mathrm{~L}^{-1}$, maximum $1.793 \pm 0.005 \mathrm{~g} \mathrm{~L}^{-1}$, minimum $1.355 \pm 0.025 \mathrm{~g} \mathrm{~L}^{-1}$ ). No significant difference was found in the average biomass concentration (ANOVA, $F_{58,59}=2.516, p=0.118$ ). Comparing the average biomass productivity (Fig. 5B) as $0.005 \pm 0.103 \mathrm{~g} \mathrm{~L}^{-1} \mathrm{day}^{-1}$ for strain Showa and $0.001 \pm 0.094 \mathrm{~g} \mathrm{~L}^{-1} \mathrm{day}^{-1}$ for strain Bot22, which was around zero for both strains, no significant differences were found between the strains (ANOVA, $F_{58,59}=0.054$, $p=0.817)$. The maximum and minimum daily biomass productivity for strain Showa was $0.187 \pm 0.006$ and $-0.185 \pm 0.009 \mathrm{~g} \mathrm{~L}^{-1} \mathrm{day}^{-1}$, respectively, in the same range as that of strain Bot22 with $0.182 \pm 0.004$ and $-0.182 \pm 0.009 \mathrm{~g} \mathrm{~L}^{-1} \mathrm{day}^{-1}$, respectively.

Looking at the concentration of extracellular hydrocarbons in the biomass (Fig. 5C), strong fluctuations were measured during the extraction period of 30 days. The average concentration of extracellular hydrocarbons in the biomass of strain Showa with $0.538 \pm 0.098$ $\mathrm{g} \mathrm{g}_{\mathrm{DW}}{ }^{-1}$ was significantly higher than that of strain Bot22 with $0.417 \pm 0.141 \mathrm{~g} \mathrm{~g}_{\mathrm{DW}}{ }^{-1}$ (ANOVA, $F_{58,59}=14.626$, $p<0.05$ ). While the maximum concentration of extracellular hydrocarbons was in the same range with $0.708 \pm 0.041 \mathrm{~g} \mathrm{~g}_{\mathrm{DW}}{ }^{-1}$ (Showa) and $0.667 \pm 0.024 \mathrm{~g} \mathrm{~g}_{\mathrm{DW}}{ }^{-1}$ (Bot22) (deviation of 6\%), the difference in the minimum detected hydrocarbon concentration was relatively high with $0.322 \pm 0.040 \mathrm{~g} \mathrm{~g}_{\mathrm{DW}}{ }^{-1}$ (Showa) and $0.183 \pm 0.060 \mathrm{~g} \mathrm{~g}_{\mathrm{DW}}{ }^{-1}$ (Bot22) (deviation of $43 \%$ ).

A significant difference was observed between the two B. braunii strains Showa and Bot22 (Fig. 5D and Table 3 ) in terms of volumetric (ANOVA, $F_{58,59}=7.148$, 
Table 2 Comparison of average biomass productivity, volumetric productivity of extracted hydrocarbons, and biomass-associated productivity of extracted hydrocarbon during short-term in situ extrac- tion over 7 days of the B. braunii strains Showa and Bot22 at starting biomass concentrations of $1.5 \mathrm{~g} \mathrm{~L}^{-1}$ and $2.5 \mathrm{~g} \mathrm{~L}^{-1}$. Values represent mean $\pm \mathrm{SD}(n=3)$

\begin{tabular}{|c|c|c|c|c|c|c|c|}
\hline \multirow[t]{2}{*}{ Strain } & \multirow{2}{*}{$\begin{array}{l}t_{E X T}[\mathrm{~min}] \\
A t_{E X T, e f f} \\
{\left[m^{2} s L^{-1}\right]}\end{array}$} & \multicolumn{3}{|c|}{$c_{D W, \text { Start }}=1.5 \mathrm{gL}^{-1}$} & \multicolumn{3}{|c|}{$c_{D W, \text { Start }}=2.5 \mathrm{gL}^{-1}$} \\
\hline & & $\begin{array}{l}P_{D W} \\
{\left[g L^{-1} d a y^{-1}\right]}\end{array}$ & $\begin{array}{l}P_{H C, E X T} \\
{\left[m g L^{-1} d a y^{-1}\right]}\end{array}$ & $\begin{array}{l}P_{H C, E X T} \\
{\left[m g g_{D W}^{-1} d a y^{-1}\right]}\end{array}$ & $\begin{array}{l}P_{D W} \\
{\left[g L^{-1} d a y^{-1}\right]}\end{array}$ & $\begin{array}{l}P_{H C, E X T} \\
{\left[m g L^{-1} d a y^{-1}\right]}\end{array}$ & $\begin{array}{l}P_{H C, E X T} \\
{\left[m g g_{D W}^{-1} d a y^{-1}\right]}\end{array}$ \\
\hline \multirow[t]{7}{*}{ Showa } & $\begin{array}{l}50 \\
14\end{array}$ & $\begin{array}{r}0.149 \\
\pm 0.009\end{array}$ & $\begin{array}{c}1.422 \\
\pm 0.531\end{array}$ & $\begin{array}{c}0.690 \\
\pm 0.252\end{array}$ & $\begin{array}{r}0.167 \\
\pm 0.010\end{array}$ & $\begin{array}{c}2.275 \\
\pm 0.344\end{array}$ & $\begin{array}{c}0.752 \\
\pm 0.151\end{array}$ \\
\hline & $\begin{array}{l}100 \\
55\end{array}$ & $\begin{array}{r}0.130 \\
\pm 0.019\end{array}$ & $\begin{array}{c}1.537 \\
\pm 0.156\end{array}$ & $\begin{array}{c}0.797 \\
\pm 0.171\end{array}$ & $\begin{array}{r}0.154 \\
\pm 0.012\end{array}$ & $\begin{array}{c}2.485 \\
\pm 0.462\end{array}$ & $\begin{array}{c}0.842 \\
\pm 0.172\end{array}$ \\
\hline & $\begin{array}{l}150 \\
123\end{array}$ & $\begin{array}{r}0.113 \\
\pm 0.012\end{array}$ & $\begin{array}{c}2.614 \\
\pm 0.566\end{array}$ & $\begin{array}{c}1.408 \\
\pm 0.220\end{array}$ & $\begin{array}{r}0.123 \\
\pm 0.007\end{array}$ & $\begin{array}{l}4.305 \\
\pm 0.576\end{array}$ & $\begin{array}{c}1.473 \\
\pm 0.257\end{array}$ \\
\hline & $\begin{array}{l}200 \\
218\end{array}$ & $\begin{array}{r}0.025 \\
\pm 0.012\end{array}$ & $\begin{array}{c}4.020 \\
\pm 0.654\end{array}$ & $\begin{array}{c}2.389 \\
\pm 0.403\end{array}$ & $\begin{array}{r}0.071 \\
\pm 0.004\end{array}$ & $\begin{array}{c}5.536 \\
\pm 0.750\end{array}$ & $\begin{array}{c}2.021 \\
\pm 0.267\end{array}$ \\
\hline & $\begin{array}{l}250 \\
341\end{array}$ & $\begin{array}{r}0.023 \\
\pm 0.009\end{array}$ & $\begin{array}{l}11.232 \\
\pm 1.105\end{array}$ & $\begin{array}{c}6.922 \\
\pm 0.627\end{array}$ & $\begin{array}{r}0.043 \\
\pm 0.012\end{array}$ & $\begin{array}{l}18.881 \\
\pm 1.765\end{array}$ & $\begin{array}{c}6.969 \\
\pm 0.565\end{array}$ \\
\hline & $\begin{array}{l}300 \\
491\end{array}$ & $\begin{array}{c}-0.005 \\
\pm 0.004\end{array}$ & $\begin{array}{l}16.185 \\
\pm 1.202\end{array}$ & $\begin{array}{l}10.632 \\
\pm 0.759\end{array}$ & $\begin{array}{r}-0.011 \\
\pm 0.007\end{array}$ & $\begin{array}{l}26.102 \\
\pm 2.675\end{array}$ & $\begin{array}{l}10.655 \\
\pm 1.171\end{array}$ \\
\hline & $\begin{array}{l}350 \\
669\end{array}$ & $\begin{array}{c}-0.106 \\
\pm 0.013\end{array}$ & $\begin{array}{l}25.090 \\
\pm 1.200\end{array}$ & $\begin{array}{l}19.723 \\
\pm 2.909\end{array}$ & $\begin{array}{r}-0.109 \\
\pm 0.017\end{array}$ & $\begin{array}{l}53.171 \\
\pm 2.955\end{array}$ & $\begin{array}{l}24.397 \\
\pm 2.131\end{array}$ \\
\hline \multirow[t]{5}{*}{ Bot 22} & $\begin{array}{l}50 \\
14\end{array}$ & $\begin{array}{r}0.097 \\
\pm 0.016\end{array}$ & $\begin{array}{c}4.702 \\
\pm 0.534\end{array}$ & $\begin{array}{c}2.438 \\
\pm 0.444\end{array}$ & $\begin{array}{r}0.129 \\
\pm 0.011\end{array}$ & $\begin{array}{c}6.917 \\
\pm 0.756\end{array}$ & $\begin{array}{c}2.448 \\
\pm 0.268\end{array}$ \\
\hline & $\begin{array}{l}100 \\
55\end{array}$ & $\begin{array}{r}0.064 \\
\pm 0.016\end{array}$ & $\begin{array}{c}7.582 \\
\pm 1.478\end{array}$ & $\begin{array}{c}4.221 \\
\pm 0.843\end{array}$ & $\begin{array}{r}0.095 \\
\pm 0.006\end{array}$ & $\begin{array}{l}13.055 \\
\pm 2.745\end{array}$ & $\begin{array}{c}4.723 \\
\pm 1.125\end{array}$ \\
\hline & $\begin{array}{l}150 \\
123\end{array}$ & $\begin{array}{r}0.054 \\
\pm 0.014\end{array}$ & $\begin{array}{l}11.426 \\
\pm 1.969\end{array}$ & $\begin{array}{c}6.918 \\
\pm 0.972\end{array}$ & $\begin{array}{r}0.065 \\
\pm 0.009\end{array}$ & $\begin{array}{l}18.912 \\
\pm 3.310\end{array}$ & $\begin{array}{c}6.943 \\
\pm 1.073\end{array}$ \\
\hline & $\begin{array}{l}200 \\
218\end{array}$ & $\begin{array}{r}0.008 \\
\pm 0.005\end{array}$ & $\begin{array}{l}16.750 \\
\pm 2.318\end{array}$ & $\begin{array}{l}10.479 \\
\pm 1.294\end{array}$ & $\begin{array}{r}-0.008 \\
\pm 0.005\end{array}$ & $\begin{array}{l}25.701 \\
\pm 1.378\end{array}$ & $\begin{array}{l}10.813 \\
\pm 0.579\end{array}$ \\
\hline & $\begin{array}{l}250 \\
341\end{array}$ & $\begin{array}{c}-0.096 \\
\pm 0.014\end{array}$ & $\begin{array}{l}29.114 \\
\pm 4.500\end{array}$ & $\begin{array}{l}19.952 \\
\pm 1.277\end{array}$ & $\begin{array}{r}-0.070 \\
\pm 0.014\end{array}$ & $\begin{array}{l}53.246 \\
\pm 8.930\end{array}$ & $\begin{array}{l}22.176 \\
\pm 2.777\end{array}$ \\
\hline
\end{tabular}

$p=0.010$ ) and biomass-associated productivity (ANOVA, $\left.F_{58,59}=7.131, p=0.010\right)$ of the extracted hydrocarbons during long-term in situ extraction. The average volumetric hydrocarbon productivity of strain Showa $\left(16.989 \pm 3.241 \mathrm{mg} \mathrm{L}^{-1} \mathrm{day}^{-1}\right)$ was $17 \%$ higher than that of strain Bot22 (14.526 $\left.\pm 3.866 \mathrm{mg} \mathrm{L}^{-1} \mathrm{day}^{-1}\right)$. This higher volumetric hydrocarbon productivity of strain Showa was also reflected in the biomass-associated hydrocarbon productivity, which was also $13 \%$ higher than that of strain Bot22 over the 30 days of in situ extraction. The total extracted hydrocarbon yield over 30 days of extraction was $509.66 \pm 95.61 \mathrm{mg} \mathrm{L}^{-1}$ for strain Showa, a $17 \%$ higher value than for strain Bot 22 . On average, approximately $1 \%$ of the culture system biomass was extracted as hydrocarbons for both strains. Comparing the yield of extracted hydrocarbons associated with total biomass, $10 \%$ more hydrocarbons were extracted using strain Showa $\left(31.48 \pm 5.90 \%_{\text {DW }}\right)$ than strain Bot22 $\left(28.33 \pm 7.41 \%_{\text {DW }}\right)$.

If the daily volumetric- and biomass-associated hydrocarbon productivity is put in relation to the respective concentration of extracellular hydrocarbons in the biomass (Fig. 6), a direct correlation was found for both strains. With increasing concentration of extracellular hydrocarbons in the biomass, the productivity of extracted hydrocarbons also increases during the process of in situ extraction.

\section{Discussion}

In addition to biological impact factors such as growth, hydrocarbon concentration, and solvent compatibility (Jackson et al. 2017, 2020; Kleinert and Griehl 2021), the process of in situ extraction or "milking" of $B$. braunii is mainly influenced by the effective extraction time, i.e., the time each culture suspension particle remains in contact with the solvent, and the phase boundary, the area between solvent and culture suspension created for the transfer of extracellular hydrocarbons (Räbiger et al. 2010). In the in situ extraction process used for this study by Griehl et al. (2015), the culture suspension is dispersed in the solventcontaining extraction column by a nozzle. Depending on the applied volume flow, the solvent properties, and the diameter of the nozzle, a temporally determined amount of culture suspension particles (drops of culture suspension containing 
Fig. 5 Growth curve (A), daily biomass productivity (B), daily concentration of extracellular hydrocarbons in the biomass (C), and biomass-associated productivity of extracted hydrocarbons (D) of the two B. braunii strains Showa and Bot22 during a 30-day longterm in situ extraction applying the strain-dependent optimal extraction time. Values represent mean $\pm \operatorname{SD}(n=3)$
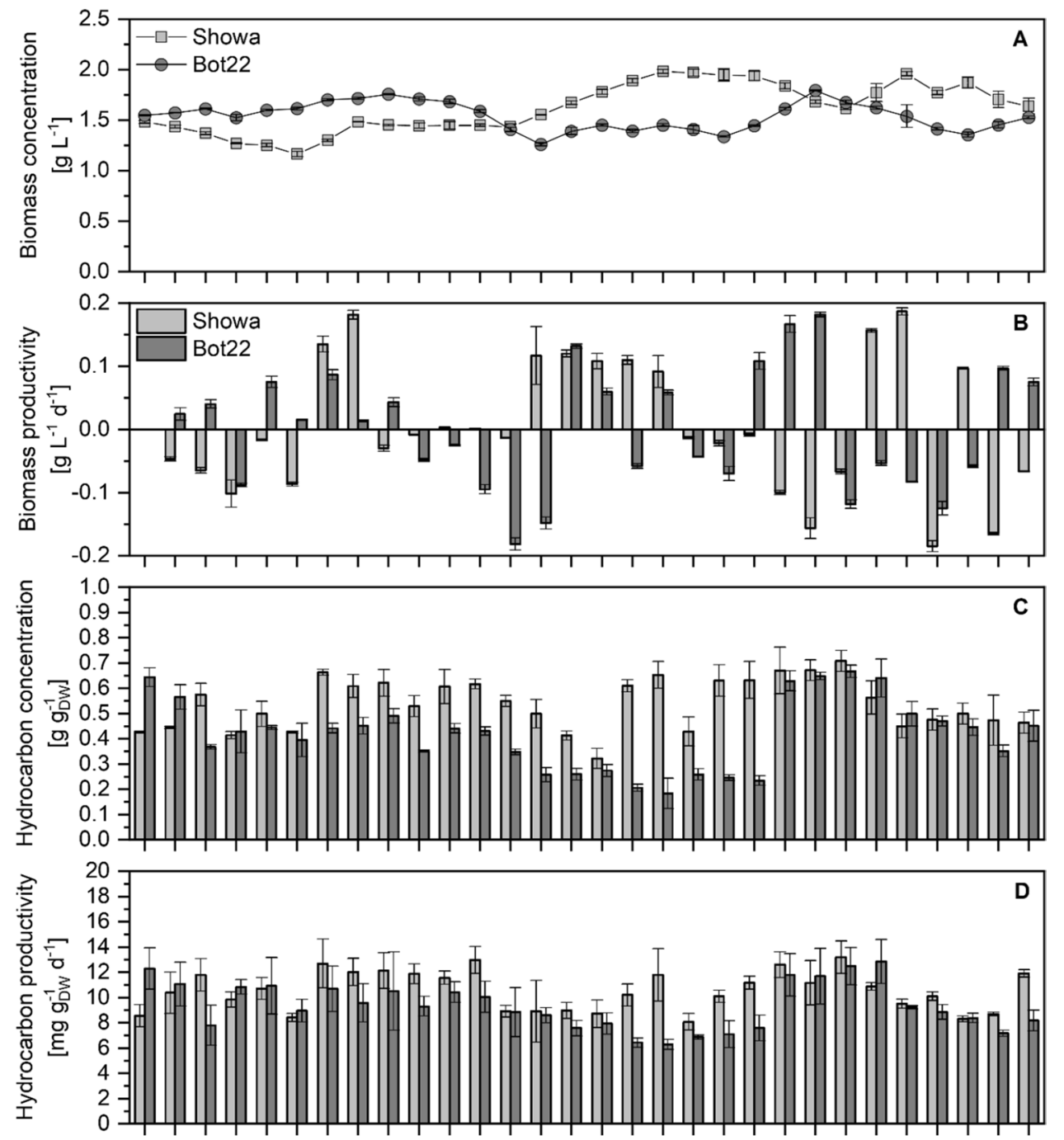

$122 \quad 3 \quad 4 \quad 5 \quad 6 \quad 7 \quad 8 \quad 9101112131415161718192021222324252627282930$

Time [d]
Table 3 Comparison of the extraction parameters determined for the two B. braunii strains Showa and Bot22 during 30-day long-term in situ extractions applying the strain-dependent optimal extraction time. Values represent mean $\pm \mathrm{SD}(n=3)$

\begin{tabular}{llcc}
\hline & & \multicolumn{1}{l}{ Showa } & \multicolumn{1}{l}{ Bot22 } \\
\hline$c_{D W, \text { Start }}$ & {$\left[g L^{-1}\right]$} & $1.482 \pm 0.012$ & $1.547 \pm 0.005$ \\
$\varnothing_{D W}$ & {$\left[g L^{-1}\right]$} & $1.619 \pm 0.238$ & $1.538 \pm 0.135$ \\
$P_{D W}$ & {$\left[g L^{-1} d a y^{-1}\right]$} & $0.005 \pm 0.103$ & $0.001 \pm 0.094$ \\
$\varnothing_{H C}$ & {$\left[g_{E H C} g_{D W}^{-1}\right]$} & $0.538 \pm 0.098$ & $0.417 \pm 0.139$ \\
$P_{H C, E X T}$ & {$\left[\mathrm{mg}_{H C} L^{-1} d a y^{-1}\right]$} & $16.989 \pm 3.241$ & $14.526 \pm 3.866$ \\
$P_{H C, E X T}$ & {$\left[\mathrm{mg}_{H C} g_{D W}^{-1} d a y^{-1}\right]$} & $10.534 \pm 1.544$ & $9.338 \pm 1.852$ \\
$Y_{H C, E X T}$ & {$\left[m g_{H C} L^{-1}\right]$} & $509.66 \pm 95.61$ & $435.31 \pm 114.03$ \\
$Y_{H C, E X T}$ & {$\left[\% \varnothing_{D W}\right]$} & $31.48 \pm 5.90$ & $28.33 \pm 7.41$ \\
\hline
\end{tabular}

several colonies of $B$. braunii) with a characteristic diameter was generated either by periodic particle formation or by jet disintegration in the solvent (Räbiger et al. 2010). Depending on the particle properties, the solvent height, and the total volume of extracted culture suspension, the culture suspension droplets pass through the solvent in a certain time (effective extraction time). Based on the particle dimensions and the solvent properties, a specific particle surface area is generated during the extraction time (effective extraction surface area). In addition to the extraction parameters described above, the extraction efficiency is also influenced by the physiological condition of the culture suspension. Since a negative influence on the physiological conditions of the culture suspension occurs with increasing contact time between the solvent and the culture suspension, a compromise between extraction efficiency and culture vitality must be found in order to continue the in situ 
Fig. 6 Correlation of biomassassociated (top) and volumetric (bottom) productivity of extracted hydrocarbons with the concentration of extracellular hydrocarbons in the biomass of the two B. braunii strains Showa and Bot22 during a 30-day long-term in situ extraction applying the strain-dependent optimal extraction time. Values represent mean $\pm \mathrm{SD}(\mathrm{n}=3)$
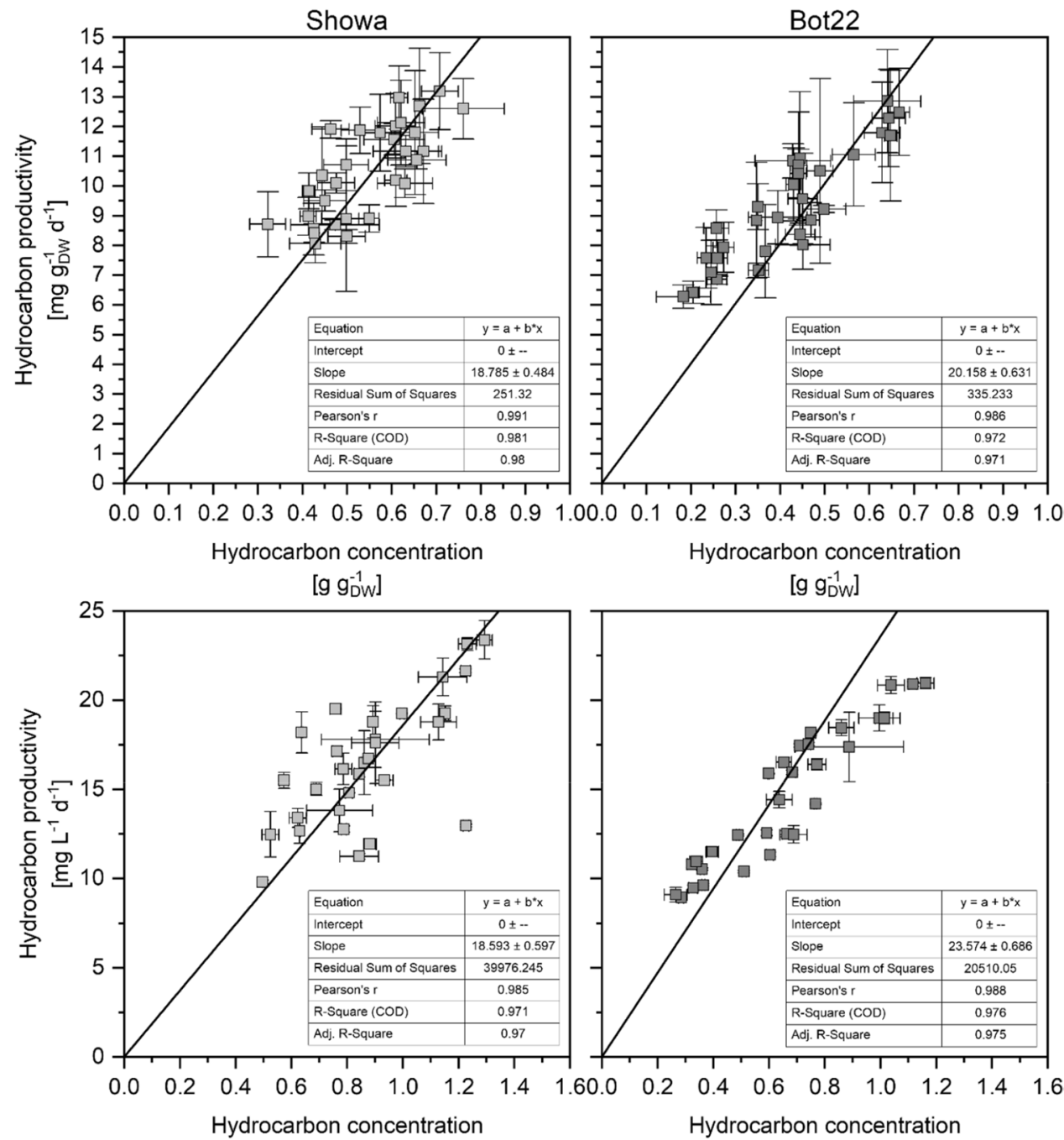

$\left[\mathrm{g} \mathrm{L}^{-1}\right.$ ]
Hydrocarbon concentration

[g $g_{D W}^{-1}$ ]

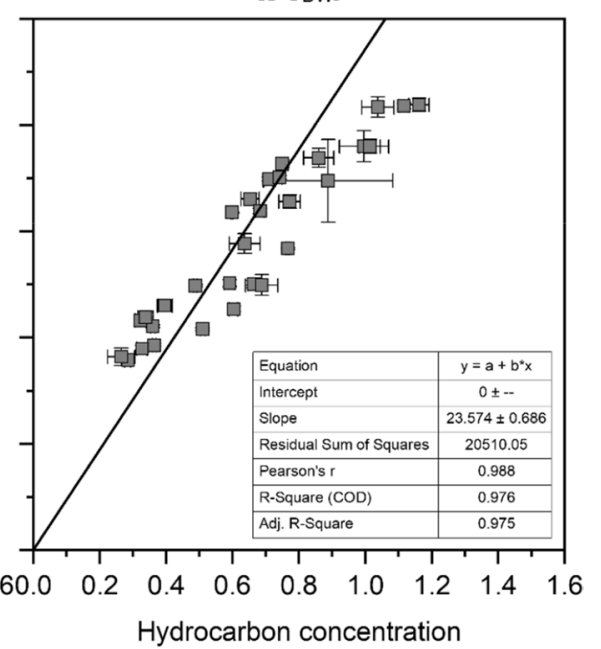

[g L-1] extraction process as long as possible (Griehl et al. 2015). Indeed, as described in our previous study (Kleinert and Griehl 2021), only a few B. braunii strains have been investigated for the process of in situ extraction with different procedural designs of the extraction process (Griehl et al. 2015; Jackson et al. 2017, 2020; Mehta et al. 2019). Accordingly, it was not possible to derive optimal extraction parameters for the in situ extraction of the two B. braunii strains Showa and Bot22 from the literature. In the absence of information on optimal extraction parameters, a consistent cross-strain design of the in situ extraction process was established in this study to determine the optimal straindependent extraction time of the two promising $B$. braunii strains Showa and Bot22. While gradually increasing the extraction time, the optimal effective extraction time and phase boundary for the respective strain were determined based on the growth of the treated culture suspension. In our opinion, the point of optimal extraction time is reached when the biomass concentration in the culture system remains constant, where the growth of the culture just compensates the negative impact of the solvent (daily biomass productivity is nearly zero). Therefore, the daily increase or decrease in biomass (biomass productivity) was applied as an indicator for cell viability during this study. However, methods such as the biomass productivity (An et al. 2004) or the oxygen production (Frenz et al. 1989) as an indicator for cell vitality are only reflecting the whole culture. A more detailed method for determining the cell vitality which would include the single cells is seen in measuring the quantum yield of photosystem II with PAMfluorometry (Jackson et al. 2017) before and after solvent exposure. With view of a potential scale-up, where analytics has to be kept as simple as possible and for keeping the experiments during this study manageable, measurement of PAM-fluorometry was not considered for this study.

During the 7-day short-term experiments, an optimal extraction time at which the growth of the culture suspension just compensates for the negative influence of the solvent was found to be $300 \mathrm{~min}_{\mathrm{day}^{-1}}$ for strain Showa and 200 min day $^{-1}$ for strain Bot 22 for the two starting biomass 
concentrations of 1.5 and $2.5 \mathrm{~g} \mathrm{~L}^{-1}$. These extraction times correspond to an extraction coefficient of $464 \mathrm{~m}^{2} \mathrm{~s} \mathrm{~L}_{\text {Susp }}{ }^{-1}$ at an effective extraction time of $12.91 \mathrm{~s} \mathrm{day}^{-1}$ for strain Showa and $206 \mathrm{~m}^{2} \mathrm{~s} \mathrm{~L}_{\text {Susp }}{ }^{-1}$ at an effective extraction time of $8.61 \mathrm{~s} \mathrm{day}^{-1}$ for strain Bot22. In this study, a negative effect on cell viability was observed at extraction times $>8.607 \mathrm{~s} \mathrm{day}^{-1}$ by strain Bot22, whereas Mehta et al. (2019) measured no negative effect on cell viability at effective extraction times of 84 and $276 \mathrm{~s} \mathrm{day}^{-1}$ for the same strain. This serious difference in the effective extraction time when using the same strain could be explained on the one hand by the solvent used and on the other hand by the phase boundary area generated. The biocompatibility of the solvent increases with higher $\log P_{\text {Oct }}$ values (Frenz et al. 1989). Mehta et al. (2019) were using $n$-dodecane with a $\log P_{\text {Oct }}$ value of 6.1 for their extraction experiments, while $n$-hexane with a $\log P_{\text {Oct }}$ value of 4.0 was used in this study. Generally, solvents with a longer chain length such as $n$-heptane, $n$-octane, or $n$-dodecane with increased $\log P_{\text {Oct }}$ values seem to be more biocompatible to B. braunii (Jackson et al. 2017; Kleinert and Griehl 2021). Besides biocompatibility of the solvent, which has to be recovered after extraction, the boiling point of the solvent is influencing the economics of the in situ extraction process. Therefore, the solvent $n$-hexane is seen as the favored solvent with the best compromise between solvent recovery, extraction efficiency, and biocompatibility (Jackson et al. 2017). Taking into account the phase boundary area created by the in situ extraction of Mehta et al. (2019) puts the higher effective extraction time into perspective. Mehta et al. (2019) created a phase boundary of $0.0204 \mathrm{~m}^{2}$ with an effective extraction time of $276 \mathrm{~s} \mathrm{day}^{-1}$, whereas in this study a phase boundary area of $23.99 \mathrm{~m}^{2}$ was generated with an effective extraction time of $8.61 \mathrm{~s} \mathrm{day}^{-1}$. When calculating the extraction coefficient $\left(A t_{\mathrm{EXT}, \text { eff }}\right)$ from these values, the value of Mehta et al. (2019) of $5.63 \mathrm{~m}^{2} \mathrm{~s} \mathrm{~L}_{\mathrm{Susp}}{ }^{-1}$ was noticeably lower compared to $206 \mathrm{~m}^{2} \mathrm{~s} \mathrm{~L}_{\mathrm{Susp}}{ }^{-1}$ in this study. Thus, the calculation of the extraction coefficient established in this study explains the better biocompatibility measured by Mehta et al. (2019). The results indicate that the simultaneous consideration of both factors (effective extraction time and phase boundary area) is important for the performance of the in situ extraction process. Nevertheless, the extraction coefficient determined during this study as optimal for the respective strain was calculated based on static literature values such as the density, viscosity, or surface tension for the culture suspension and solvent (Table 1). On the one hand, this value's underlying changes of physical nature and were influenced by temperature, which tried to be kept constant as possible during the experiments. On the other hand, these values might be influenced by the culture such as a changing viscosity based on secreted extracellular polysaccharides reported for $B$. braunii (Díaz Bayona and Garcés 2014; García-Cubero et al. 2018).
An increased viscosity was not observed optically during all expedients in this study. However, a changing viscosity could not be excluded and has to be kept in mind, especially when it comes to longer extraction or culturing periods, as $B$. braunii continuously can release this polysaccharide (García-Cubero et al. 2018).

When comparing the optimal extraction time of the two strains Showa and Bot22, a lower optimal extraction time was observed for strain Bot22. Griehl et al. (2015) investigated two A race strains (SAG 807-1 and CCAP 807/2) and one B race strain (SCCAP K-1761). They found no negative influence on cell viability with an effective extraction time of $36 \mathrm{~s} \mathrm{day}^{-1}$ for strain SAG 807-1, while an effective extraction time of $12 \mathrm{~s} \mathrm{day}^{-1}$ for strains CCAP 807/2 and SCCAP K-1761 led to a decrease in biomass concentration. Based on the limited information from the literature, no statement could be made about the effective extraction time. However, a significant influence on the solvent compatibility could be assumed due to the morphological characteristics of the respective $B$. braunii strain. The colony size of strain Showa was found to be smaller compared to that of strain Bot22 (ESM 2) and the cells in the colony are more densely arranged in strain Showa compared to Bot22 (Fig. 2). This compact arrangement of the cells in the colonies of strain Showa probably results in a higher resistance to negative environmental influences (Furuhashi et al. 2016b). This could explain the different optimal extraction times of the two strains, as well as a longer extraction time required for strain Showa, which consists of more compact colonies, to cause a negative effect of the solvent, compared to strain Bot22 with a looser colony structure. Furthermore, there is a possibility that small amounts of solvent remain in the space between the more loosely arranged cells (Furuhashi et al. 2016b). This would cause stainable damage to the cells, as $n$-hexane is able to damage the plasma membrane of the cells and thus penetrate into the cells (Kleinegris et al. 2011; Moheimani et al. 2013).

Considering the average hydrocarbon productivity at optimum extraction time and starting biomass concentration of $1.5 \mathrm{~g} \mathrm{~L}^{-1}$, no major differences were observed between strain Showa with $16.19 \mathrm{mg} \mathrm{L}^{-1}$ day $^{-1}$ (10.63 $\mathrm{mg} \mathrm{g}_{\mathrm{DW}}{ }^{-1} \mathrm{day}^{-1}$ ) and strain Bot22 with $16.75 \mathrm{mg} \mathrm{L}^{-1} \mathrm{day}^{-1}\left(10.48 \mathrm{mg} \mathrm{g}_{\mathrm{DW}}{ }^{-1} \mathrm{day}^{-1}\right)$. Similar values were detected when inoculating with a biomass concentration of $2.5 \mathrm{~g} \mathrm{~L}^{-1}$. However, due to the $66 \%$ increase in biomass in the system, a $60 \%$ increase in volumetric hydrocarbon productivity was observed for both strains Showa and Bot22 (approx. $26 \mathrm{mg} \mathrm{L}^{-1}$ day $^{-1}$ ). Irrespective of the starting biomass concentration, identical values were measured for the biomass-associated hydrocarbon productivity with approx. $11 \mathrm{mg} \mathrm{g}_{\mathrm{Dw}}{ }^{-1} \mathrm{day}^{-1}$. Based on these results, the influence of the biomass concentration in the culture system on the biomass-associated hydrocarbon 
productivity could be largely excluded. In contrast, volumetric hydrocarbon productivity is directly influenced by biomass concentration. Mehta et al. (2019) determined an average hydrocarbon productivity of $6.4 \mathrm{mg} \mathrm{L}^{-1}$ day $^{-1}$ and $3.6 \mathrm{mg} \mathrm{g}_{\mathrm{DW}}{ }^{-1}$ day $^{-1}$ using strain Bot22 over 7 days and a similar experimental design with the solvent $n$-dodecane. As mentioned earlier, the extraction coefficient used by Mehta et al. (2019) is lower than the optimal extraction coefficient determined in this study, which would explain the higher hydrocarbon productivity achieved in this study. Moheimani et al. (2014) determined an average hydrocarbon productivity of $11.63 \mathrm{mg} \mathrm{L}^{-1}$ day $^{-1}$ with strain Bot22 over 70 days (14 extraction cycles) of in situ extraction using the solvent $n$-heptane. This value obtained by Moheimani et al. (2014) is difficult to compare with the values from this study as the in situ extraction procedure used in their study (mixing of culture suspension and solvent on an orbital shaker) is not comparable to the column extraction procedure used in our study. For strain Showa, no comparable studies are currently available in the literature. Comparing the two strains Showa and Bot 22 with themselves, the identical hydrocarbon productivity could be explained by the concentration of extracellular hydrocarbons in the biomass. In our previous study (Kleinert and Griehl 2021), an almost identical extracellular hydrocarbon concentrations of $49.3 \%$ (Showa) and 51.6\% (Bot22) was measured for both strains.

For a better significance of the results for the determination of the strain-dependent optimal extraction time, long-term in situ extractions were carried out over 30 days under optimal extraction time and a starting biomass concentration of $1.5 \mathrm{~g} \mathrm{~L}^{-1}$. The average biomass productivity over 30 days was $0.005 \pm 0.103 \mathrm{~g} \mathrm{~L}^{-1} \mathrm{day}^{-1}$ for strain Showa and $0.001 \pm 0.094 \mathrm{~g} \mathrm{~L}^{-1} \mathrm{dAay}^{-1}$ for strain Bot22, close to zero for both strains and identical to those of the 7-day in situ extractions. These values support the previously achieved results that at optimal extraction coefficient, the growth of the culture suspension just compensates for the negative effects of the solvent. Furthermore, the stagnation of biomass in the culture system with simultaneous hydrocarbon extraction indicates the functioning of the in situ extraction process of $B$. braunii compared to the classical process chain, as no increase in biomass concentration is intended (Griehl et al. 2015; Jackson et al. 2017).

For strain Showa, an almost identical average hydrocarbon productivity of $16.99 \mathrm{mg} \mathrm{L}^{-1}$ day $^{-1}\left(10.53 \mathrm{mg} \mathrm{g}_{\mathrm{DW}}{ }^{-1}\right.$ day $^{-1}$ ) was achieved during the 30-day in situ extraction compared to the 7-day short-term extractions, whereas for strain Bot22, a reduced hydrocarbon productivity of $14.53 \mathrm{mg} \mathrm{L}^{-1}$ day $^{-1}$ (10.48 $\mathrm{mg} \mathrm{g}_{\mathrm{DW}}{ }^{-1} \mathrm{day}^{-1}$ ) was measured compared to the 7-day extractions. Considering the average concentration of hydrocarbon in the biomass, this difference between the two strains could be explained. As displayed in Fig. 6, a direct correlation between hydrocarbon productivity and the concentration of external hydrocarbons in the biomass was found for both strains. With $0.417 \pm 0.139 \mathrm{~g} \mathrm{~g}_{\mathrm{DW}}{ }^{-1}$, a reduced average extracellular hydrocarbon concentration was measured for strain Bot22 compared to strain Showa $\left(0.538 \pm 0.098 \mathrm{~g} \mathrm{~g}_{\mathrm{DW}}{ }^{-1}\right)$ during the 30-day in situ extraction, explaining the reduced hydrocarbon productivity. According to Chaudry et al. (2018) and Jackson et al. (2020), increasing the extracellular hydrocarbon concentration is a key factor in increasing the economics of the in situ extraction process. The reason for the comparatively low extracellular hydrocarbon concentration of approx. $42 \%$ DW for strain Bot 22 during the 30-day extraction could have many causes. For example, the cultivation conditions of the preculture could have a lasting influence on the behavior of a microalgal culture under investigation (Kojima and Zhang 1999). Furthermore, small changes in culture conditions such as nutrient concentration could lead to morphological changes in $B$. braunii colonies (Tanoi et al. 2014; Furuhashi et al. 2016a), which in turn affects the concentration of extracellular hydrocarbons. During the experiments in this study, great care was taken to keep cultivation and extraction parameters constant. However, manual control of most of the process parameters and thus a change in the initial values during the duration of the experiments could not be fully excluded. To exclude a methodical error for extracellular hydrocarbon determination (see "Materials and methods"), where the culture suspension was filtered through glass fiber filters and extracellular hydrocarbons might washed out like residual salts and polysaccharides, the filtrates of one set of the biological replicates $(n=30)$ from the 30-day extraction experiment of Showa and Bot22 (initially stored as backup at $-20{ }^{\circ} \mathrm{C}$ ) were analyzed in terms of extractable lipids. Therefore, the method described in ESM 3 was used. For strain Showa, a washed out hydrocarbon content of $1.23 \mathrm{mg} \mathrm{L}^{-1}(n=30)$ and for Bot22 of $1.37 \mathrm{mg} \mathrm{L}^{-1}(n=30)$ was measured. These values correspond to $0.15 \%$ (Showa) and $0.21 \%$ (Bot22) of the average hydrocarbon content determined in the biomass. Therewith a washing out of hydrocarbons trough filtration could also be excluded.

Comparing the hydrocarbon productivity achieved in this study with other publications (Table 4), a hydrocarbon productivity for strain Bot22 of $11.63 \mathrm{mg} \mathrm{L}^{-1}$ day $^{-1}$ was published by Moheimani et al. (2014). Compared to the A race strains, the hydrocarbon productivity of the $B$ race strains investigated in this study and in the literature is noticeably higher. Moheimani et al. (2013) achieved a hydrocarbon productivity between 3 and $7 \mathrm{mg} \mathrm{g}_{\mathrm{DW}}{ }^{-1}$ day $^{-1}$ with the A race strain CCAP 807/2 during a 7-day in situ extraction and Griehl et al. (2015) measured an average hydrocarbon productivity of $1.3 \mathrm{mg} \mathrm{g}_{\mathrm{DW}}{ }^{-1}$ day $^{-1}$ during a 30-day in situ extraction with the A race strain SAG 807-1. The high concentration of extracellular hydrocarbons (up to $86 \%_{\mathrm{DW}}$ ) as well 
Table 4 Comparison of the results for in situ extraction determined during this study with the experiments out of literature

\begin{tabular}{|c|c|c|c|c|c|c|}
\hline Strain (race) & Solvent & Type of extraction & Duration & Extraction cycles & Hydrocarbon recovery & Reference \\
\hline $\begin{array}{l}\text { UTEX } \\
572(\mathrm{~A})\end{array}$ & n-Octane & $\begin{array}{l}\text { Column extraction with two bubble } \\
\text { columns }\end{array}$ & 4 days & 4 cycles & $57 \%$ of total lipids & An et al. 2004 \\
\hline \multirow[t]{2}{*}{$\begin{array}{l}\text { CCAP } \\
807 / 2(\mathrm{~A})\end{array}$} & $n$-Heptane & $\begin{array}{l}\text { Mixer-settler with Erlenmeyer } \\
\text { flasks }\end{array}$ & 7 days & 4 cycles & $3-7 \mathrm{mg} \mathrm{g}_{\mathrm{DW}}{ }^{-1} \mathrm{day}^{-1}$ & Moheimani et al. 2013 \\
\hline & $n$-Hexane & Column extraction & 5 days & 5 cycles & $\begin{array}{l}8.7 \mathrm{mg} \mathrm{g}_{\mathrm{DW}}^{-1} \text { day }^{-1} \\
5.5 \mathrm{mg} \mathrm{L}^{-1} \mathrm{day}^{-1}\end{array}$ & Griehl et al. 2015 \\
\hline \multirow[t]{2}{*}{$\begin{array}{l}\text { SAG } \\
807-1(\mathrm{~A})\end{array}$} & $n$-Hexane & Column extraction & 5 days & 5 cycles & $\begin{array}{l}1.2-2.7 \mathrm{mg} \mathrm{g}_{\mathrm{DW}}{ }^{-1} \mathrm{day}^{-1} \\
2.5-4.4 \mathrm{mg} \mathrm{L}^{-1} \mathrm{day}^{-1}\end{array}$ & Griehl et al. 2015 \\
\hline & $n$-Hexane & Column extraction & 40 days & 30 cycles & $\begin{array}{l}1.3 \mathrm{mg} \mathrm{g}_{\mathrm{DW}^{-1}}{ }^{-1} \mathrm{day}^{-1} \\
2.7 \mathrm{mg} \mathrm{L}^{-1} \mathrm{day}^{-1}\end{array}$ & Griehl et al. 2015 \\
\hline $\begin{array}{l}\text { FACHB } \\
357 \text { (N/A) }\end{array}$ & Tetradecane & $\begin{array}{l}\text { Column extraction with membrane } \\
\text { for spouting the solvent in the } \\
\text { culture }\end{array}$ & 4 days & 4 cycles & $50 \%$ of total lipids & Zhang 2013 \\
\hline \multirow[t]{5}{*}{ Bot22 (B) } & $n$-Heptane & $\begin{array}{l}\text { Mixer-settler with Erlenmeyer } \\
\text { flasks }\end{array}$ & 70 days & 16 cycles & $12 \mathrm{mg} \mathrm{L}^{-1}$ day $^{-1}$ & Moheimani et al. 2014 \\
\hline & $n$-Heptane & $\begin{array}{l}\text { Mixer-settler with Erlenmeyer } \\
\text { flasks }\end{array}$ & 15 days & 3 cycles & $\begin{array}{l}7-29 \mathrm{mg} \mathrm{g}_{\mathrm{DW}}^{-1} \mathrm{day}^{-1} \\
9.5-43 \mathrm{mg} \mathrm{L}^{-1} \mathrm{day}^{-1}\end{array}$ & Jackson et al. 2019 \\
\hline & $n$-Dodecane & Mixer-settler with shake flasks & 7 days & $\begin{array}{l}\text { Continuous con- } \\
\text { tact to solvent }\end{array}$ & $\begin{array}{l}2.8 \mathrm{mg} \mathrm{g}_{\mathrm{DW}}^{-1} \mathrm{day}^{-1} \\
4.7 \mathrm{mg} \mathrm{L}^{-1} \mathrm{day}^{-1}\end{array}$ & Mehta et al. 2019 \\
\hline & $n$-Dodecane & Column extraction & 7 days & 7 cycles & $\begin{array}{l}3.6 \mathrm{mg} \mathrm{g}_{\mathrm{DW}}{ }^{-1} \mathrm{day}^{-1} \\
6.4 \mathrm{mg} \mathrm{L}^{-1} \mathrm{day}^{-1}\end{array}$ & Mehta et al. 2019 \\
\hline & $n$-Hexane & Column extraction & 30 days & 30 cycles & $\begin{array}{l}9.3 \mathrm{mg} \mathrm{g}_{\mathrm{DW}^{-1} \mathrm{day}^{-1}} \\
14.5 \mathrm{mg} \mathrm{L}^{-1} \mathrm{day}^{-1}\end{array}$ & This study \\
\hline Showa (B) & $n$-Hexane & Column extraction & 30 days & 30 cycles & $\begin{array}{l}10.5 \mathrm{mg} \mathrm{g}_{\mathrm{DW}}^{-1} \mathrm{day}^{-1} \\
16.9 \mathrm{mg} \mathrm{L}^{-1} \mathrm{day}^{-1}\end{array}$ & This study \\
\hline $\begin{array}{l}\text { SCCAP } \\
1761(B)\end{array}$ & $n$-Hexane & Column extraction & 5 days & 5 cycles & $\begin{array}{l}32-59 \mathrm{mg} \mathrm{g}_{\mathrm{DW}}^{-1} \mathrm{day}^{-1} \\
26-33 \mathrm{mg} \mathrm{L}^{-1} \mathrm{day}^{-1}\end{array}$ & Griehl et al. 2015 \\
\hline
\end{tabular}

as the higher hydrocarbon productivities achieved demonstrates the higher suitability of the $\mathrm{B}$ race strains for the process of in situ extraction (Borowitzka 2018). A comparison of the results for in situ extraction of strains Showa and Bot 22 with the literature is given in Table 4.

In conclusion, the B. braunii strains Showa and Bot22, which were identified in our previous study during batch cultivation experiments (Kleinert and Griehl 2021) as potential candidates for the process of in situ extraction, also proved to be suitable during the real in situ extraction experiments. By determining the strain-dependent optimal extraction time, a successful long-term in situ extraction over 30 days was realized for both strains. It was shown that a characterization of the in situ extraction requires the consideration of the effective extraction time and the realized phase boundary surface of culture suspension and solvent. With the calculation of the extraction coefficient, both values were combined to form a characteristic extraction value, which is suitable for transferring the obtained results to other extraction systems and setups. Furthermore, the extracellular hydrocarbon concentration in the biomass was identified as a critical parameter for the process of in situ extraction. For further investigations and a precise consideration of the process economics, the in situ extraction process of the B. braunii strains Showa and Bot 22 is planned to be scaled up to a higher culture volume and the culture conditions optimized with regard to a higher growth rate and higher hydrocarbon concentration in the biomass.

Supplementary Information The online version contains supplementary material available at https://doi.org/10.1007/s10811-021-02633-7.

Acknowledgements We would like to thank Prof. Dr. Shigeru Okada from the Faculty and Graduate School of Agriculture and Life Science / University of Tokyo for providing the Botryococcus braunii strain var. Showa. Furthermore, we thank Prof. Dr. Makoto M. Watanabe from the Algae Biomass and Energy System R\&D Center / University of Tsukuba for making the Botryococcus braunii strain Bot22 available for us. Thank goes to Prof. Dr. Thomas Friedl from the Department Experimental Phycology and Culture Collection of Algae (EPSAG) of the Georg-August-University Goettingen for general support during this study.

Author contribution Experiments were planned, conducted, and analyzed by Christian Kleinert. The manuscript was written by Christian Kleinert and reviewed by Carola Griehl. Funding was realized by Carola Griehl. 
Funding Open Access funding enabled and organized by Projekt DEAL. Research was founded by the Ministry for Food and Agriculture Germany (BMEL/Fachagentur Nachwachsende Rohstoffe e. V.) under the award number 22017618.

Data availability All data generated or analyzed during this study are included in this published article and its supplementary information file.

\section{Declarations}

Conflict of interest The authors declare no competing interests.

Open Access This article is licensed under a Creative Commons Attribution 4.0 International License, which permits use, sharing, adaptation, distribution and reproduction in any medium or format, as long as you give appropriate credit to the original author(s) and the source, provide a link to the Creative Commons licence, and indicate if changes were made. The images or other third party material in this article are included in the article's Creative Commons licence, unless indicated otherwise in a credit line to the material. If material is not included in the article's Creative Commons licence and your intended use is not permitted by statutory regulation or exceeds the permitted use, you will need to obtain permission directly from the copyright holder. To view a copy of this licence, visit http://creativecommons.org/licenses/by/4.0/.

\section{References}

Acién FG, Fernández JM, Magán JJ, Molina E (2012) Production cost of a real microalgae production plant and strategies to reduce it. Biotechnol Adv 30:1344-1353

An JY, Sim SJ, Kim BW, Lee JS (2004) Improvement of hydrocarbon recovery by two-stage cell-recycle extraction in the cultivation of Botryococcus braunii. J Microbiol Biotechnol 14:932-937

Baba M, Kikuta F, Suzuki I, Watanabe MM, Shiraiwa Y (2012) Wavelength specificity of growth, photosynthesis, and hydrocarbon production in the oil-producing green alga Botryococcus braunii. Bioresour Technol 109:266-270

Bhadana B, Tyagi RD (2019) Milking of lipids from oleaginous microorganisms. In: Tyagi RD, Surampalli RY, Zhang TC, Yan S, Zhang X (eds) Biodiesel production. Technologies, challenges, and future prospects. American Society of Civil Engineers, Reston, VA, pp 383-396

Borowitzka MA (2018) Biology of microalgae. In: Levine IA, Fleurence $\mathbf{J}$ (eds) Microalgae in health and disease prevention. Elsevier, London, pp 23-72

Borowitzka MA, Moheimani NR (2013) Sustainable biofuels from algae. Mitigat Adapt Strat Global Change 18:13-25

Chaudry S, Bahri PA, Moheimani NR (2018) Techno-economic analysis of milking of Botryococcus braunii for renewable hydrocarbon production. Algal Res 31:194-203

Choi SP, Bahn S-H, Sim SJ (2013) Improvement of hydrocarbon recovery by spouting solvent into culture of Botryococcus braunii. Bioprocess Biosyst Eng 36:1977-1985

Díaz Bayona KC, Garcés LA (2014) Effect of different media on exopolysaccharide and biomass production by the green microalga Botryococcus braunii. J Appl Phycol 26:2087-2095

Frenz J, Largeau C, Casadevall E, Kollerup F, Daugulis AJ (1989) Hydrocarbon recovery and biocompatibility of solvents for extraction from cultures of Botryococcus braunii. Biomass Bioenerg 34:755-762

Furuhashi K, Hasegawa F, Saga K, Kudou S, Okada S, Kaizu Y, Imou K (2016a) Effects of culture medium salinity on the hydrocarbon extractability, growth and morphology of Botryococcus braunii. Biomass Bioenerg 91:83-90

Furuhashi K, Noguchi T, Okada S, Hasegawa F, Kaizu Y, Imou K (2016b) The surface structure of Botryococcus braunii colony prevents the entry of extraction solvents into the colony interior. Algal Res 16:160-166

García-Cubero R, Cabanelas ITD, Sijtsma L, Kleinegris DMM, Barbosa MJ (2018) Production of exopolysaccharide by Botryococcus braunii CCALA 778 under laboratory simulated Mediterranean climate conditions. Algal Res 29:330-336

Griehl C, Kleinert C, Griehl C, Bieler S (2015) Design of a continuous milking bioreactor for non-destructive hydrocarbon extraction from Botryococcus braunii. J Appl Phycol 27:1833-1843

Hejazi MA, Wijffels RH (2004) Milking of microalgae. Trends Biotechnol 22:189-194

Jackson BA, Bahri PA, Moheimani NR (2017) Repetitive nondestructive milking of hydrocarbons from Botryococcus braunii. Renew Sust Energ Rev 79:1229-1240

Jackson BA, Bahri PA, Moheimani NR (2019) Repetitive extraction of botryococcene from Botryococcus braunii: a study of the effects of different solvents and operating conditions. J Appl Phycol 31:3491-3501

Jackson BA, Bahri PA, Moheimani NR (2020) Non-destructive extraction of lipids from Botryococcus braunii and its potential to reduce pond area and nutrient costs. Algal Res 47:101833

Khoo KS, Chew KW, Yew GY, Leong WH, Chai YH, Show PL, Chen W-H (2020) Recent advances in downstream processing of microalgae lipid recovery for biofuel production. Bioresour Technol 304:122996

Kleinegris DMM, van Es MA, Janssen M, Brandenburg WA, Wijffels RH (2011) Phase toxicity of dodecane on the microalga Dunaliella salina. J Appl Phycol 23:949-958

Kleinert C, Griehl C (2021) Identification of suitable Botryococcus braunii strains for non-destructive in situ hydrocarbon extraction. J Appl Phycol 33:785-798

Kojima E, Zhang K (1999) Growth and hydrocarbon production of microalga in bubble column photobioreactors. J Biosci Bioeng $87: 811-815$

Mehta P, Jackson BA, Nwoba EG, Vadiveloo A, Bahri PA, Mathur AS, Moheimani NR (2019) Continuous non-destructive hydrocarbon extraction from Botryococcus braunii BOT-22. Algal Res 41:101537

Melis A (2013) Carbon partitioning in photosynthesis. Curr Opin Chem Biol 17:453-456

Moheimani NR, Cord-Ruwisch R, Raes E, Borowitzka MA (2013) Non-destructive oil extraction from Botryococcus braunii (Chlorophyta). J Appl Phycol 25:1653-1661

Moheimani NR, Matsuura H, Watanabe MM, Borowitzka MA (2014) Non-destructive hydrocarbon extraction from Botryococcus braunii BOT-22 (race B). J Appl Phycol 26:1453-1463

Räbiger N, Schlüter M, Mersmann A, Dahl HD (2010) L4 bubble and drops in technical equipment. In: VDI heat atlas, 2nd edn. Springer, Heidelberg, pp 1239-1270

Rippka R, Stanier RY, Deruelles J, Herdman M, Waterbury JB (1979) Generic assignments, strain histories and properties of pure cultures of cyanobacteria. J Gen Microbiol 111:1-61

Schlüter M (2018) Bildung und Bewegung von Tropfen und Blasen in technischen Apparaten. In: Stephan P, Mewes D, Kabelac S, Kind M, Schaber K, Wetzel T (eds) VDI-Wärmeatlas: Fachlicher Träger 
VDI-Gesellschaft Verfahrenstechnik und Chemieingenieurwesen. Springer, Berlin, pp 1-19

Tanoi T, Kawachi M, Watanabe MM (2014) Iron and glucose effects on the morphology of Botryococcus braunii with assumption on the colony formation variability. J Appl Phycol 26:1-8

Zhang F, Cheng LH, Xu XH, Zhang L, Chen HL (2013) Application of membrane dispersion for enhanced lipid milking from FACHB 357. J Biotechnol 165:22-29
Zhang J (2013) Culture of Botryococcus braunii. Master Thesis. Murdoch University, Perth

Publisher's note Springer Nature remains neutral with regard to jurisdictional claims in published maps and institutional affiliations. 